\title{
Nonlinear Analysis of the Seismic Response of a Reinforced Concrete Structure Built in High Seismic Region in Algeria
}

\author{
Imane Djafar Henni, Abdelkader Bougara and Amar Kassoul \\ Laboratory of Structures, Geotechnics and Risks, Department of Civil Engineering, Hassiba Benbouali University, Chlef, BP 151, \\ Algeria
}

\begin{abstract}
The objective of this paper is to analyze the seismic response of a reinforced concrete structure dimensioned according to the Algerian seismic rules. First, we expose the approach of nonlinear time history method. Next, we describe a ten-storey reinforced concrete building braced by shear walls, implanted in the high seismicity region in Algeria. This structure is submitted to different seismic records. Finally, we analyze and interpret the seismic response in function of the deformability, shear strength, flexural strength and the bearing capacity under the compressive stress together with the local ductility. The results obtained showed that the identified structure represents a satisfied nonlinear behavior under the seismic recording of medium intensity contrary that obtained under higher earthquake of El Centro which remains unacceptable and requests a constructive improvement in the Algerian seismic rules.
\end{abstract}

Key words: Seismic response, building, nonlinear dynamic analysis, seismic recording.

\section{Introduction}

The structures located in northern Algeria are often subject to the risk of damage induced by severe seismic actions. However, the intensity of seismic forces acting on a building is conditioned not only by the characteristics of seismic motion, but also by various structural properties and the type of bracing. In seismic areas, the type of bracing often used is the shear walls; when considering their capacity of resistance and ductility. Many numerical studies have been conducted to study the nonlinear seismic response of reinforced concrete structures braced by shear walls. Memari et al. [1] conducted a seismic analysis performed on a 32-storey reinforced concrete building. The methods used included the static analysis and dynamic linear and nonlinear using sophisticated software programs. The variable parameters are the formation of plastic hinges and inter-story drift. They concluded that the

Corresponding author: Amar Kassoul, professor, research fields: structural engineering.E-mail: amkassoul@hotmail.com. limits of inter-story drift in the codes do not predict necessarily the degree of damage that this type of construction can support during an earthquake. Llera et al. [2] have proposed a simplified model based on shear and torsion. The results illustrated that plastic hinges were held during the first cycle of the response, and the building has shown highly nonlinear torsional behavior despite his symmetry plane. In the same context, Gicev and Trifunac [3] explain why the principal damages of the building, damaged by the 1994 Northridge earthquake in California, are localized in the tops of columns of the fourth floor, using the non-linear one-dimensional model. The results illustrate that this approach is more reliable to locate the damage in a building compared to the analysis based on the pushover analysis. Mazars et al. [4] has presented a research program carried around experimentation on shaking table, where two types of finite element modeling in nonlinear dynamics are presented. Their results indicate that refined models allow access to very 
detailed information. In other study of seismic behavior of structures, Boivin and Paultre [5] have conducted a nonlinear analysis of a twelve-story ductile concrete shear wall system, designed according to National Building Code of Canada. The result indicated that the envelope of dimensioning the shear capacity is more underestimated than that predicted by the code, which increases the risk of shear failure.

However, although the northern Algeria is known for her high seismic activity, few studies have been conducted on the seismic behavior of moderately high structures, dimensioned by the Algerian seismic rules (RPA99/v2003) [6]. The aim of this paper contributes to the analysis of the seismic response of a reinforced concrete building, whose design widely used in northern Algeria, using the nonlinear time history method under some real seismic records, to highlight the parameters that control the seismic response of the structure.

\section{Resistant Forces and Ductility in Shear Wall}

\subsection{Constitutive Laws of Materials}

\subsubsection{Constitutive Laws of Concrete}

According to Eurocode 2 [7], the concrete is defined in mechanical terms by its characteristic compressive strength named $f_{c k}$. At the ultimate limit state, Eurocode 2 adopts a non-linear diagram to form parabolic-rectangle of unconfined concrete shown in Fig. 1. This diagram is defined by the relationship of stress and strain as follows:

$$
\sigma_{c}=\left\{\begin{array}{c}
f_{c d}\left[1-\left(1-\frac{\varepsilon_{c}}{\varepsilon_{c 2}}\right)^{n}\right] \text { for } 0 \leq \varepsilon_{c} \leq \varepsilon_{c 2} \\
f_{c d} \text { for } \varepsilon_{c 2} \leq \varepsilon_{c} \leq \varepsilon_{c u 2}
\end{array}\right.
$$

where, $f_{c d}$ is the calculated value of the compressive strength of concrete on cylinder, expressed by the following relationship:

$$
f_{c d}=\frac{\alpha_{c c} \cdot f_{c k}}{\gamma_{c}}
$$

where, $f_{c k}$ is the characteristic compressive cylinder strength of concrete at 28 days, $\gamma_{c}$ is the partial safety factor for concrete, $\alpha_{c c}$ is the coefficient taking account of long term effects on the compressive strength and of unfavorable effects resulting from the way the load is applied, $\varepsilon_{c}$ is the concrete compression deformation and $\varepsilon_{c 2}$ is the concrete compression deformation under the maximum stress $f_{c d}$, expressed in Ref. [7].

\subsubsection{Constitutive Laws of Steel}

According to Eurocode 2 [7], the steel is characterized by Characteristic yield strength of reinforcement $f_{y k}$, and Design yield strength of reinforcement $f_{y d}$, expressed by the relation:

$$
f_{y d}=\frac{f_{y k}}{\gamma_{s}}
$$

The design of the reinforced concrete sections according to Eurocode 2, adopts at the ultimate state [7], where a conventional stress-strain diagram is defined in Fig. 2. This diagram is characterized by the elastic elongation of the armature under maximum load $\varepsilon_{s y, d}$ $=f_{y d} / E_{s}$, where is equal at the Design yield strength of

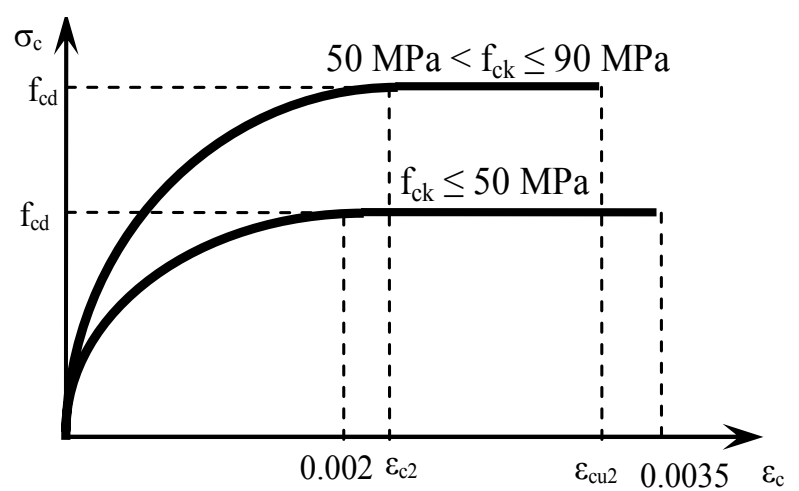

Fig. 1 Stress-strain diagram of unconfined concrete for Eurocode 2 [7].

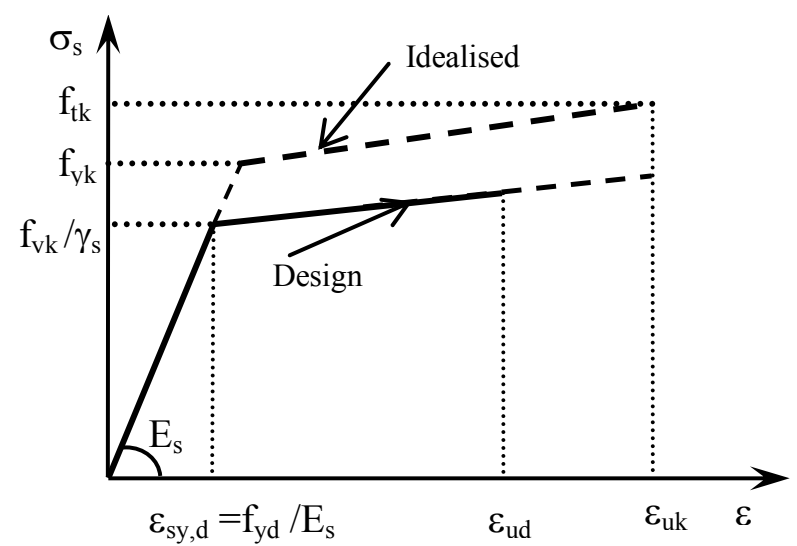

Fig. 2 Idealised and design stress-strain diagrams for reinforcing steel. 


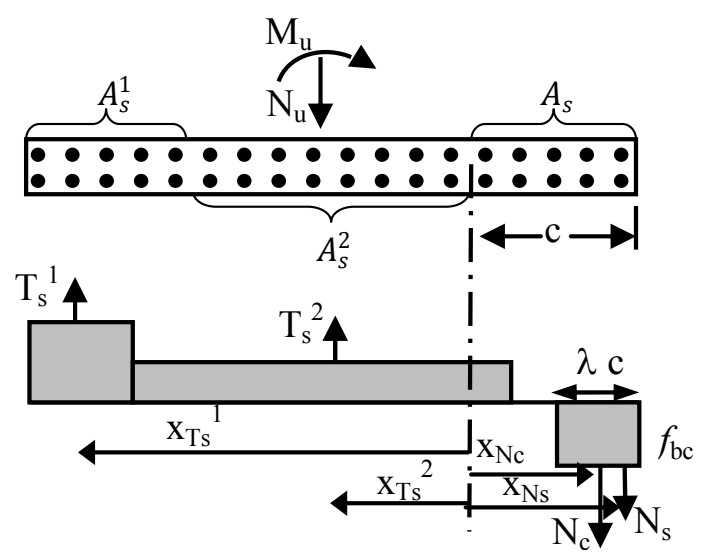

Fig. 3 Behavior of a shear wall section under the compound bending.

reinforcement $f_{y d}$ per the modulus of elasticity of steel Es takes the value of $200,000 \mathrm{Mpa}$, and the ultimate elongation of the armature under maximum load $\varepsilon_{u k}$.

\subsection{Axial Force and Bending Moment Resistant}

Fig. 3 represents the cross section of a shear wall with typical distributions of the constraints for varying positions of the neutral axis. This section is subject to a bending moment $M$ and an axial compressive force $N$. The position of the neutral axis $c$ corresponds to the most compressed fiber of shear wall.

Considering the equilibrium equations of forces acting on the section is shown in Fig. 3. The axial force $\left(N_{u}\right)$ and the bending moment resistance $\left(M_{u}\right)$ are expressed by:

$$
N_{u}=A_{s}^{1} \cdot f_{y k}+A_{s}^{2} \cdot f_{y k}-\lambda \cdot c \cdot f_{c d}-A_{s} \cdot f_{y k}
$$

$M_{u}=A_{s}^{1} \cdot f_{y k} \cdot x_{T_{s}^{1}}+A_{s}^{2} \cdot f_{y k} \cdot x_{T_{s}^{2}}+\lambda \cdot c \cdot f_{c d} \cdot x_{N_{c}}$

$$
+A_{S} \cdot f_{y k} \cdot x_{N_{S}}
$$

where, $A_{S}^{1}, A_{S}^{2}$, and $A_{S}$ are tensile reinforcement, current reinforcement and compressive reinforcement respectively.

$c$ : the distance of the compression zone.

$f_{c d}$ : the compressive strength of concrete on cylinder.

$\lambda$ : the factor defining the effective height of the compression zone that accounts for constraints simplifying (Eurocode 2), following from:

$$
\left\{\begin{array}{cc}
\lambda=0.8 & \text { for } f_{c k} \leq 50 \mathrm{Mpa} \\
\lambda=0.8-\frac{f_{c k}-50}{400} & \text { for } 50 \leq f_{c k} \leq 90 \mathrm{Mpa}
\end{array}\right.
$$

$\lambda \cdot c \cdot f_{c d}:$ is the resultant of the compressive stress in the concrete.

$x_{i}$ : is the distance between the point of force application and the neutral axis.

\subsection{Shear Resistant}

To establish the equilibrium equations, we use the analogy of Mörsch [8], which compares the operating of a reinforced concrete section with an imaginary section in lattice structure. The design formulas or control is based on the equilibrium of forces in the core. To ensure a ductile failure, Eurocode 2 [7] requires that shear resistance $\left(V_{R d}\right)$ will be the sum of the two resistance capacities (the compressed connecting rod of concrete and the horizontal reinforcement), which is equal to:

$$
V_{R d}=Z \cdot \cot \theta\left[l_{w} \cdot v_{1} \cdot f_{c d} \cdot \sin ^{2} \theta+\frac{A_{s w} \cdot f_{y w d}}{s}\right]
$$

where, $A_{s w}$ represents the cut section in the shear reinforcement. We will establish these formulas in the case of inclined angles $\theta$ (inclinations of the concrete connecting rod) and $\alpha$ (inclination of the horizontal reinforcement). Where, $l_{w}$ is the width of the shear wall, $f_{y w d}$ is the calculation of the yield strength of steel and $s$ is the spacing of the reinforcement. With $\left(Z=0.9 l_{w}\right)$ is the reduction coefficient and $v_{1}=0.6\left(1-\frac{f_{c k}}{250}\right)$.

\subsection{Curvature Ductility Factor}

The curvature ductility factor is defined as the maximum curvature $\left(\varphi_{u}\right)$ per the curvature at the beginning of plasticizing steels $\left(\varphi_{y}\right)$ [9]. It can be used as an evaluation criterion in the nonlinear time history analysis, determined by the following formula:

$$
\begin{aligned}
\mu_{\varphi}= & \frac{l_{w}\left(0.0035+0.1 \alpha_{1} \omega_{w}\right)}{2 \varepsilon_{s y . d} l_{w 0}\left(v+\omega_{v}\right)}[(1 \\
& \left.\left.-\frac{\varepsilon_{c 2 . c}}{\varepsilon_{c u 2 . c}}\right)\left(\frac{f_{c c}}{f_{c k}}\right)\left(\frac{b_{w 0} h_{w 0}}{b_{w} h_{w}}\right)+2 \omega_{v}\right]
\end{aligned}
$$

where,

$$
\begin{aligned}
& l_{w}, b_{w}, h_{w}: \text { are the dimensions of the wall. } \\
& l_{w 0}, b_{w 0}, h_{w 0}: \text { are the dimensions of the wall without }
\end{aligned}
$$
coating. 
$\varepsilon_{c 2 . c}$ is the strain at reaching the maximum strength for confined concrete.

$\varepsilon_{c u 2 . c}$ is the ultimate strain for confined concrete.

$\alpha_{1}=h_{w} / l_{w}$ is a predominant shape ratio of the wall. $\omega_{v}=A_{s}^{2} f_{y d} / b_{c} l_{w} f_{c d}$ is the mechanical ratio of vertical reinforcement.

$v=N_{E d} / b_{c} l_{w} f_{c d}:$ is the reduced axial force.

$f_{c c}:$ is the resistance of confined concrete.

$\omega_{w}$ : is the volume ratio of mechanical confinement reinforcement required in the edge members.

\section{Nonlinear Analysis Method}

The analysis of the non-linear behavior of the structure can be treated, using two types of nonlinear analysis to assess its performance, which are nonlinear static analysis and nonlinear time history analysis. The first one generates the capacity curve of the building under lateral force, which increases up to the failure, and the second one produces the dynamic response curve of building subjected to real seismic record.

\subsection{Non-linear Static (Pushover) Analysis}

The non-linear static (pushover) analysis enables to evaluate the expected collapse mechanisms, and the distribution of damage in the building. This simplified procedure allows the development of the capacity curve, by applying first the gravity loads then the monotonically increasing horizontal loads, where several methods can be used:

- The DCM (displacement coefficient method) presented in FEMA 356 [10].

- The CSM (capacity spectrum method) specified in ATC 40 [11].

- The N2 method from Eurocode 8 [12].

\subsection{Nonlinear Time History Analysis}

This method is based on direct integration of motion equations where the algorithms containing elastic-plastic deformations of the structure are adopted. This analysis is conducted using real recordings. In this method, the structure is modeled by a vertical console of nonlinear behavior, including masses associated with each node, is in fact a multiple oscillator, with a fixed base by springs and dampers (Fig. 4). The hysteresis system chosen for the nonlinear constitutive law is the 1970 Takeda modified. This method will be used in this work to analyze the nonlinear seismic response of the building. The problem resides in the choice of a proper seismic record, due to the large variability induced by the ground and the distance from the source.

The nonlinear motion equation is expressed by:

$$
M . \ddot{x}+C . \dot{x}+F_{S}(x)=-M . \ddot{x}_{g}(t)
$$

where:

$F_{s}(x)$ : is the variable rigidity of the structure;

$\ddot{x}_{g}$ : is the ground acceleration;

$\ddot{x}, \dot{x}, x$ are the acceleration, velocity and relative displacement of the structure.

The solution of Eq. (9) is obtained by the numerical integration method, using the Newmark algorithm [13] used by SAP 2000/v14.1 software.

\section{Description of Building and Loading}

\subsection{Description of Building}

The structure is a building for residential and commercial purposes, consisting of ten stories. It is located in high region seismicity $\left(\mathrm{II}_{\mathrm{b}}\right)$, on a soil class $\left(\mathrm{S}_{2}\right)$, with total height of $36.5 \mathrm{~m}$ and height of ground floor equal at $5 \mathrm{~m}$ and that of each floor equal at $3.5 \mathrm{~m}$. The material characteristics initially considered are, $30 \mathrm{Mpa}$ for compressive strength of concrete $f_{c k}$, and $500 \mathrm{Mpa}$ to yield strength of the reinforcements $f_{y k}$. The geometric data are illustrated in Fig. 5 and Table 1.

\subsection{Seismic Loading}

To avoid the introduction of response variability that could be attributed to the varying of ground motion, a series of accelerograms was established to perform this analysis. It comprises four seismic records of both directions, (NS) and (WE) each, and their most unfavorable characteristics are shown in Table 2. 


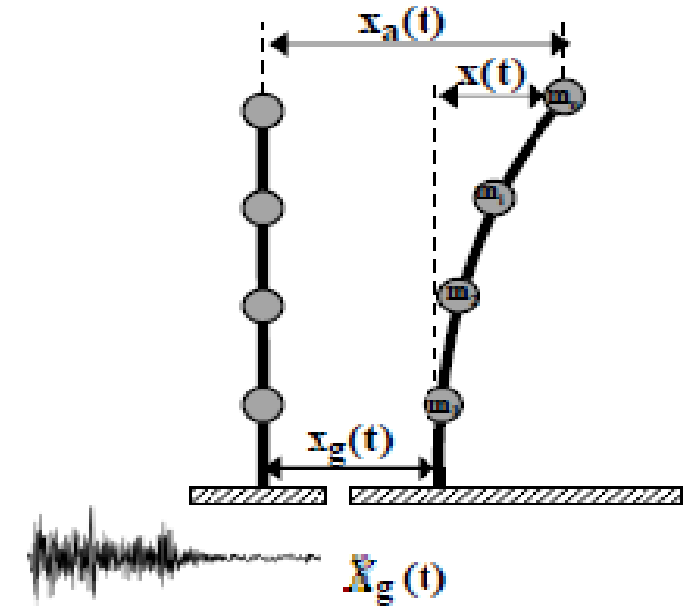

Fig. 4 Schematic representation of the oscillator under seismic excitation.

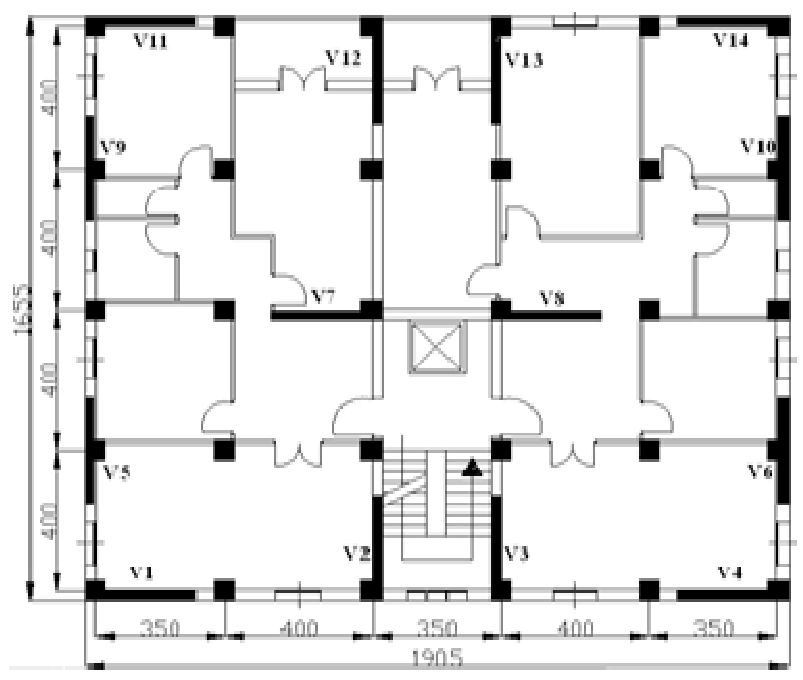

Fig. 5 Plan view of the structure.

\section{Seismic Response Analysis of Building}

\subsection{Analysis of Deformability}

The deformability is treated in terms of inter-story drift and the top displacement of the total structure.
According to seismic rules the inter-story drift for the structure should not exceed a predetermined percentage of the story height. We are interested in inter-story drift allowable of Algerian seismic rules [6] and Eurocode 8 [12] whose percentage rate is $1 \%$ and $0.75 \%$ respectively. Fig. 6 shows a confrontation between the admissible inter-story drift recommended by Ref. [6] and Ref. [12] firstly, and the horizontal relative inter-story drift obtained under different seismic recording used for the identified building. The structure analysis showed that inter-story drift for different seismic records are less than the deformations limited by the admissible $0.01 \mathrm{~h} \mathrm{[6]} \mathrm{and} 0.0075 \mathrm{~h}$ [12], except for the displacements of seven superior story obtained under the seismic record of El Centro, which are higher than that of Eurocode 8 and those obtained from the upper floors for Loma Prieta earthquake, which reached the admissible limit fixed by Eurocode 8 . We note here that the deformation field is largely great for results obtained under the local seismic records, but for high intensity seismic, the deformation is always unfavorable. In this context, it is important to note that the Algerian Seismic Rules allow a wide deformability equals to $1 \%$ of story height comparable to that of Eurocode 8 , which allows $0.75 \%$ of the story height.

The previous argument concerning the inter-story drift remains an insufficient index to measure the deformability of a structure, without knowing the global displacement of the head. In the following, we try to quantify this displacement under different seismic records to show the aptitude rate of total deformability of the structure. The Fig. 7 illustrates the

Table 1 Geometric data of the structure elements.

\begin{tabular}{|c|c|c|c|c|}
\hline & & Level & Dimension & Reinforcement \\
\hline \multirow{3}{*}{ Columns } & & $1,2,3$ & $55 \times 55 \mathrm{~cm}^{2}$ & $4 \mathrm{~T} 25+12 \mathrm{~T} 16$ \\
\hline & & $4,5,6$ & $45 \times 45 \mathrm{~cm}^{2}$ & $4 \mathrm{~T} 20+8 \mathrm{~T} 16$ \\
\hline & & $7,8,9,10$ & $35 \times 35 \mathrm{~cm}^{2}$ & $8 \mathrm{~T} 16$ \\
\hline \multirow{2}{*}{\multicolumn{2}{|c|}{ Beams }} & All levels & $30 \times 40 \mathrm{~cm}^{2}$ & $10 \mathrm{~T} 12$ \\
\hline & & $1,2,3$ & & $4 \mathrm{~T} 20+4 \mathrm{~T} 16$ \\
\hline \multirow{5}{*}{ Shear walls } & Columns & $4,5,6$ & $40 \times 40 \mathrm{~cm}^{2}$ & $8 \mathrm{~T} 16$ \\
\hline & & $7,8,9,10$ & & $8 \mathrm{~T} 14$ \\
\hline & & $1,2,3$ & & $\mathrm{~T} 12(s=10 \mathrm{~cm})$ \\
\hline & Shear walls & $4,5,6$ & $e=25 \mathrm{~cm}$ & $\mathrm{~T} 12(s=15 \mathrm{~cm})$ \\
\hline & & $7,8,9,10$ & & $\mathrm{~T} 12(s=20 \mathrm{~cm})$ \\
\hline
\end{tabular}


Table 2 Summary table characterizing the earthquakes chosen.

\begin{tabular}{llllll}
\hline Earthquake & Date & Magnitude & Location of registration & PGA (pic ground acceleration) & Direction \\
\hline El Asnam [14] & $08 / 11 / 1980$ & 5.6 & EL ASNAM & $0.211 \mathrm{~g}$ & N-S \\
Boumerdes [15] & $23 / 05 / 2003$ & 6.8 & KADDARA & $0.340 \mathrm{~g}$ & W-E \\
LomaPrieta [16] & $17 / 10 / 1989$ & 7.1 & SAN ANDREAS & $0.346 \mathrm{~g}$ & N-S \\
El Centro [17] & $19 / 05 / 1940$ & 7.2 & EL CENTRO & $0.349 \mathrm{~g}$ & N-S \\
\hline
\end{tabular}

g: gravity acceleration.

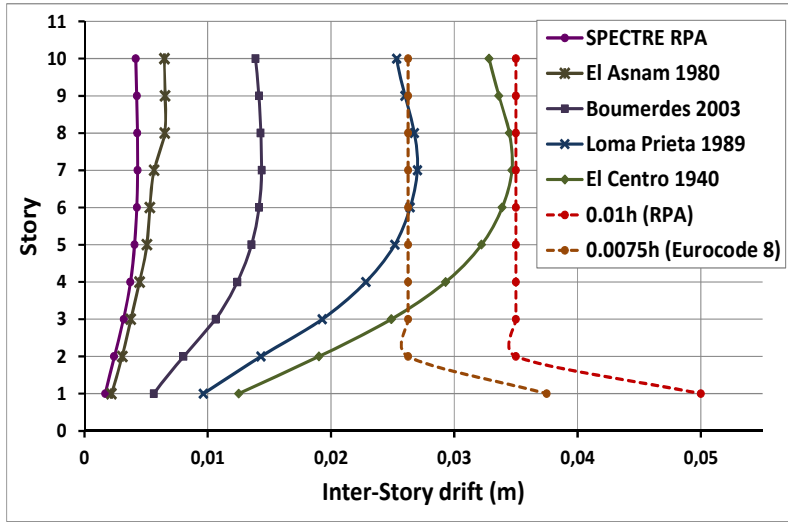

Fig. 6 Inter-story drift of structure.

results of global displacements obtained at the top of the identified structure by the nonlinear time history

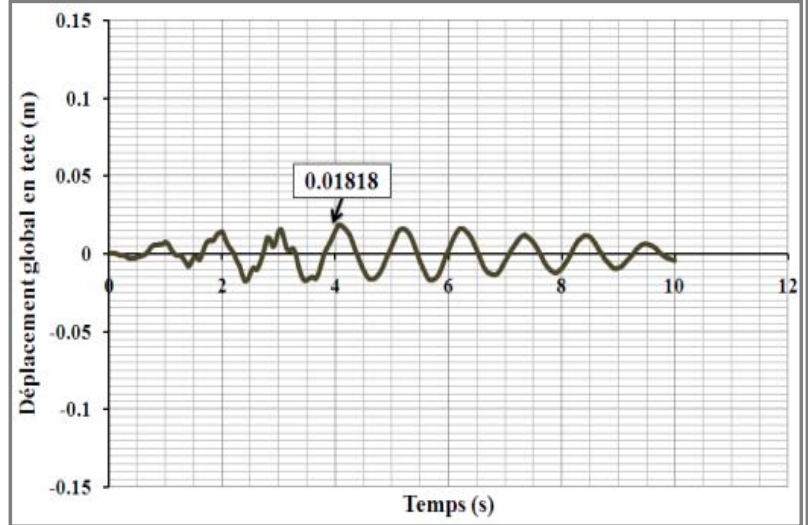

(a) El Asnam earthquake 1980.

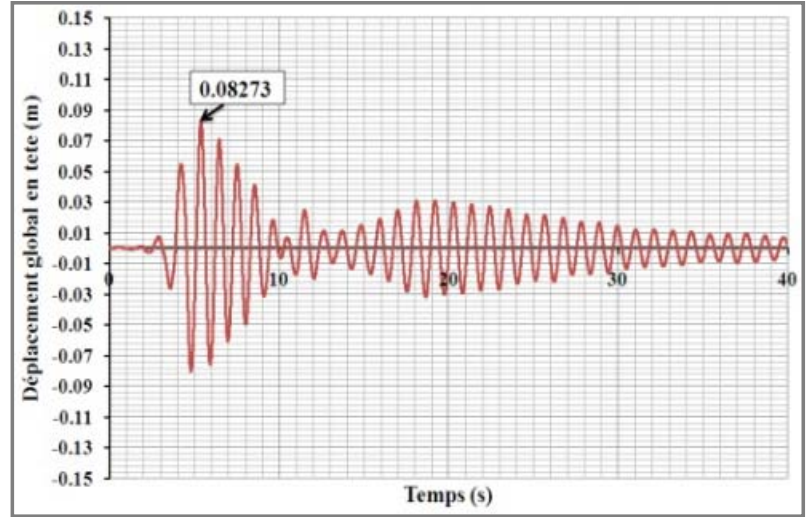

(c) Lome Prieta earthquake 1989. analysis under different seismic records mentioned above. From Fig. 7, we see that the maximum displacement under the seismic record of El Asnam reaches the value of $0.01818 \mathrm{~m}$ at $t=4.10 \mathrm{~s}$, Boumerdes $0.03695 \mathrm{~m}$ at $t=28.94 \mathrm{~s}$, Loma Prieta $0.08273 \mathrm{~m}$ at $t=5.39 \mathrm{~s}$, but under the earthquake of El Centro the displacement reaches the value of $0.1388 \mathrm{~m}$ at $\mathrm{t}=12.36 \mathrm{~s}$. It can be said here that the total displacement at the top of the structure under El Centro earthquake exceeds four and seven times that of Boumerdes and El Asnam respectively and the time to obtain the maximum displacement for El Centro earthquake is twice less and four times more than that

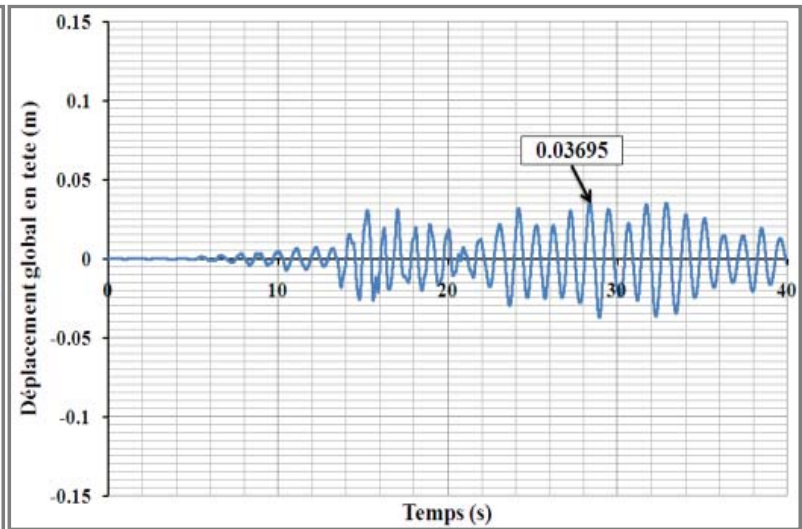

(b) Boumerdes earthquake 2003.

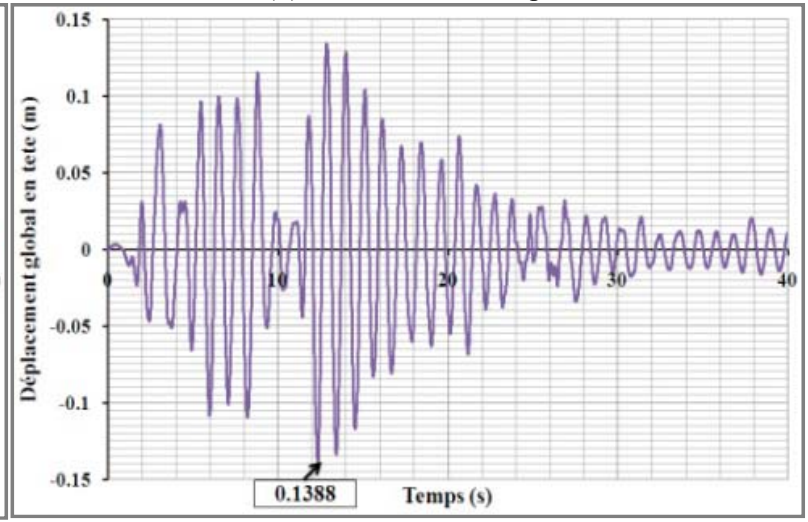

(d) El Centro earthquake 1940.

Fig. 7 Global displacement at the top of the structure in function of time. 
of Boumerdes and El Asnam respectively. Despite the difference in time of obtaining the maximum displacement, we can consider here that the local earthquakes have a very adequate non-explosive character. We note here that the structure under local earthquakes has a large deformability possible, because displacement peak under the seismic record of El Asnam and Boumerdes does not exceed $0.05 \%$ and $0.1 \%$ respectively of the total height of the structure.

\subsection{Analysis of Shear}

The results of nonlinear dynamic analysis of shear force obtained for shear walls $\left(\mathrm{V}_{8}\right.$-direction $\left.\mathrm{xx}^{\prime}\right)$ and $\left(V_{2}\right.$-direction $\left.y^{\prime}\right)$ of the structure are illustrated in Fig.8, which exposes a comparison between the shear resistance determined by Eq. (7) firstly, and those assessed under different seismic loads considered. From Fig. 8, for $\left(\mathrm{V}_{8}\right)$ wall, it is clear that the shear forces under the different seismic records used are widely less than the shear resistance, except the shear at

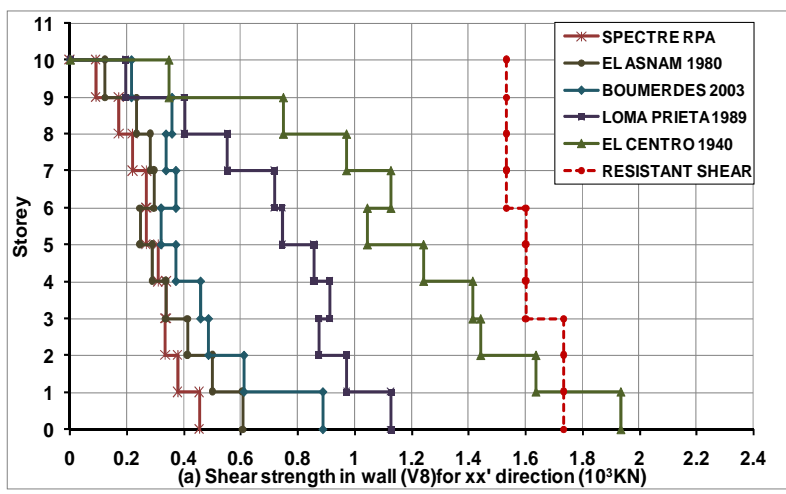

the base under El Centro earthquake, which is slightly higher. We note that the shear forces obtained under the seismic records with medium intensity at the base do not exceed $40 \%$ of the value of the resistive force contrary to that of El Centro which exceeds $10 \%$. The same observation is saved for the wall $\left(\mathrm{V}_{2}\right)$ of the direction (yy') (Fig. 8b). We note here that the structure has a good performance of the shearing force under the local earthquakes, comparatively under El Centro quake, so the structure requests rather special constructive provisions.

\subsection{Analysis of Flexural Strength}

The variations of curves of bending moments under different seismic records on the walls $\left(\mathrm{V}_{8}\right.$-direction $\left.\mathrm{xx}^{\prime}\right)$ and $\left(\mathrm{V}_{2}\right.$-sense $\left.\mathrm{yy}^{\prime}\right)$ are depicted in Fig. 9, which illustrates a comparison between the bending moment determined by Eq. (5) on the one hand, and those measured under different seismic loads considered. According to the values of the $\left(\mathrm{V}_{2}\right)$ wall, although

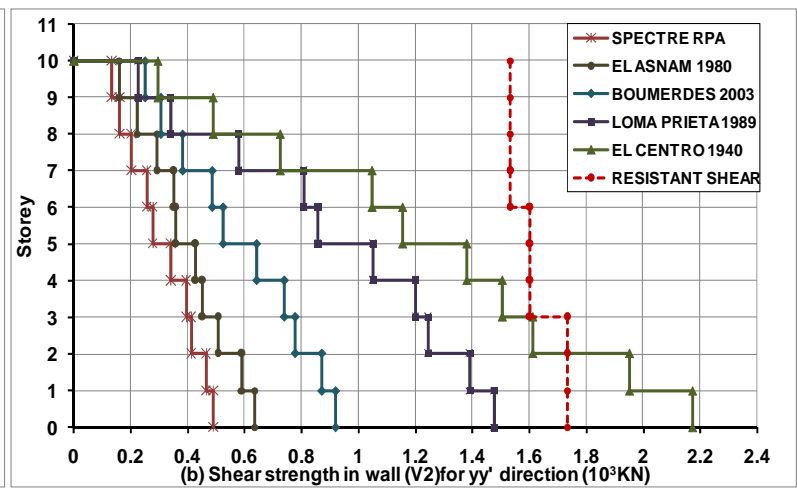

Fig. 8 Shear strength for each floor of the structure.
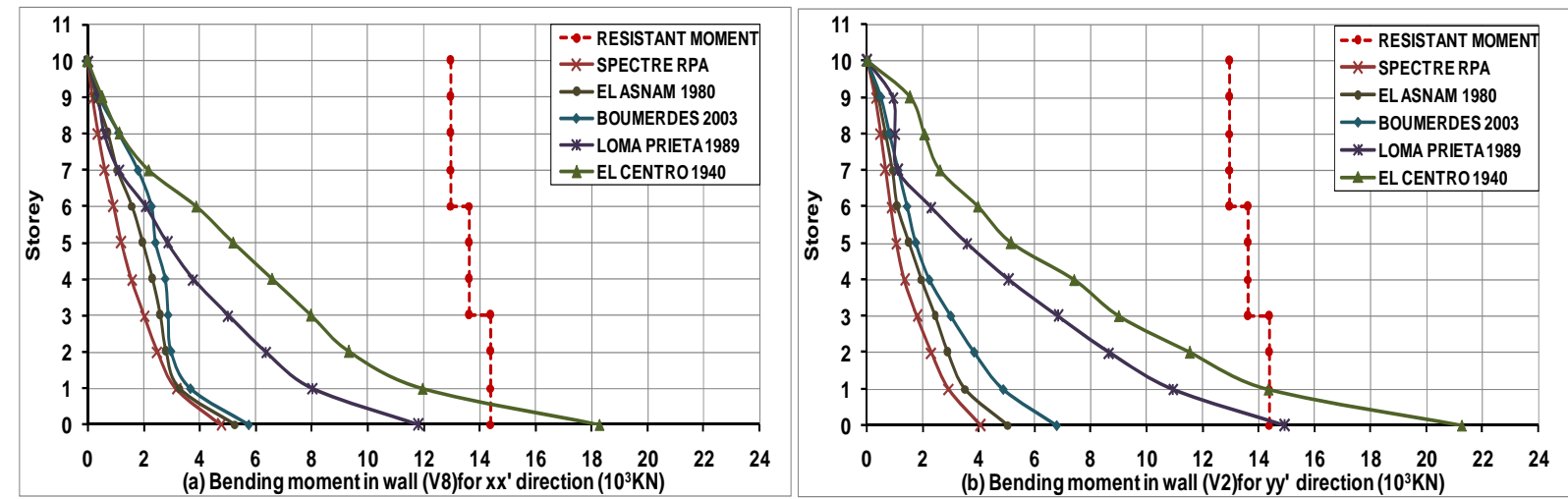

Fig. 9 Bending moment for each floor of the structure. 
bending moments under different seismic records considered are largely underside of the curve of the resisting moment, the moment at the base under El Centro quake exceeds the resistance moment with a gap of $6000 \mathrm{KN}$, and under the Loma Prieta earthquake reaches the critical value. For the (V8) wall of the opposite direction, the same behavior is observed (Fig. 9a). This shows that the shear walls dimensioned according the RPA99/v2003, assures a very adequate bending resistant under the local seismic records. However, this behavior under strong earthquakes as El Centro demands a large improvement for integration of other recommendations and constructive arrangements more distinct.

\subsection{Analysis of Bearing Capacity under Compressive} Stress

The variation of compression axial forces of the walls $\left(\mathrm{V}_{8}\right.$-direction $\left.\mathrm{xx}^{\prime}\right)$ and $\left(\mathrm{V}_{2}\right.$-sense $\left.\mathrm{yy}^{\prime}\right)$ of the structure is derived in Fig. 10, which shows a confrontation between the compressive resistant determined by Eq. (4) firstly, and the axial forces of compression determined by the nonlinear time history analysis under different seismic records considered in this study. From Fig. 10, we see that the compressive forces of the wall $\left(\mathrm{V}_{8}\right.$-direction $\left.\mathrm{xx}^{\prime}\right)$ under the spectrum regulatory of Ref. [6] and the different local seismic records of El Asnam and Boumerdes remain largely under the axial resistance. Moreover, the bearing capacity at the base of this shear wall, under the seismic record of El Centro is still insufficient where the

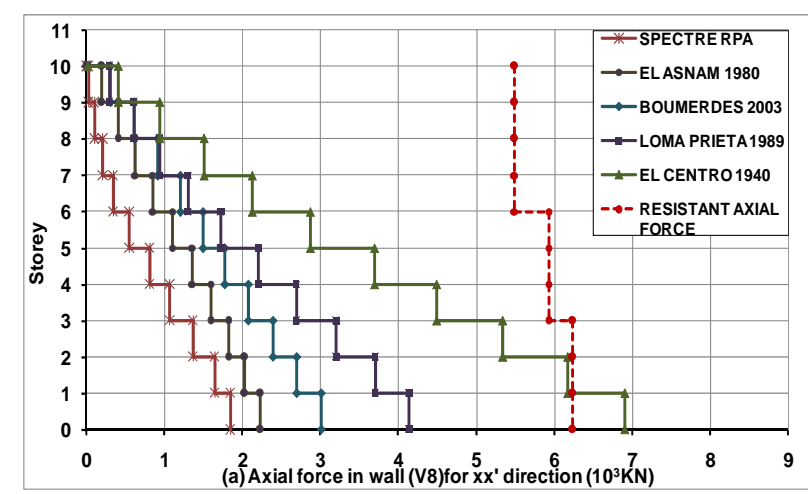

structure shows a suffering in the resistant with an excess of $1500 \mathrm{KN}$. Concerning the $\left(\mathrm{V}_{2}\right.$-sense $\left.y \mathrm{y}^{\prime}\right)$ wall, the same seismic response is found over the entire height of the shear wall and under the different seismic records. Consequently, the bearing capacity of the studied structure under compressive stress, remains not acceptable under the major earthquake intensities, which require a considerable improvement in seismic design, contrary to that obtained in the local earthquakes.

\subsection{Analysis of the Local Ductility at the Base of the Structure}

Fig. 11 shows the variation moment-curvature relationships in the shear walls $\left(\mathrm{V}_{8}\right.$-direction $\left.\mathrm{xx}^{\prime}\right)$ and $\left(V_{2}\right.$-sense $\left.y y^{\prime}\right)$ of the identified structure for the four earthquakes described in Table 2. As we have shown previously, it is possible to deduce the curvature ductility factor from these diagrams. According to Fig. 11, the curvature ductility factor of $\left(\mathrm{V}_{8}\right)$ wall varies between 16.25 and 13.98 and for $\left(\mathrm{V}_{2}\right)$ wall between 17 and 14.02 for both earthquake of El Centro and El Asnam respectively. Table 3 illustrates clearly the different curvature ductility factors corresponding to the walls (V8) and (V2) for each earthquake. From these values, it shows that the ductility is largely sufficient in these walls. However, the ductility decreases significantly with the magnitude of the earthquake; from here, we can say that the ductility demand in the structure increases with increase of the earthquake magnitude for the absorption

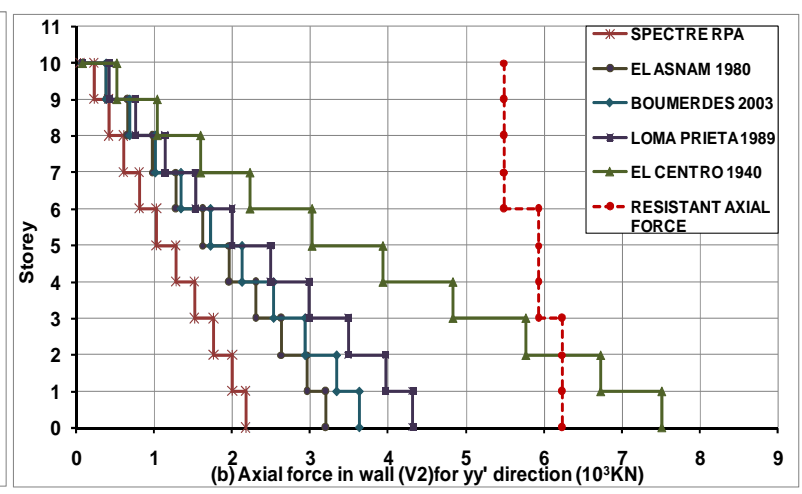

Fig. 10 Axial force for each floor of the structure. 

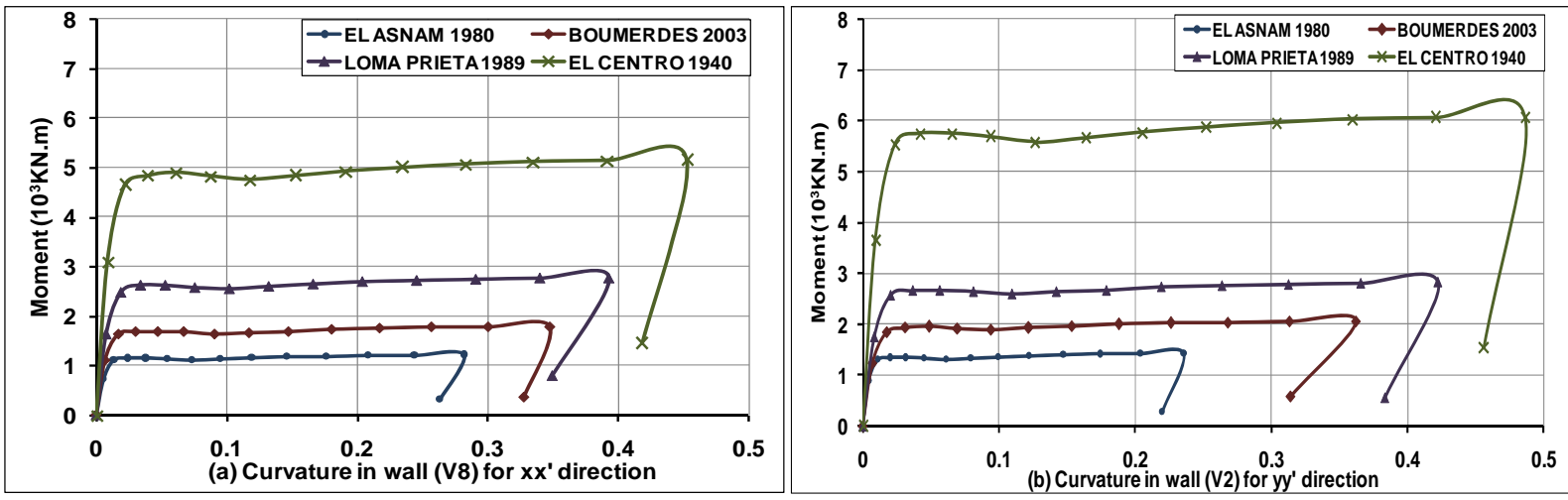

Fig. 11 Moment-cuvature diagram.

Table 3 Summary of the curvature ductility factors on the structure.

\begin{tabular}{llllll}
\hline & & El Asnam & Boumerdes & Loma Prieta & El Centro \\
\hline \multirow{3}{*}{$\left(\mathrm{V}_{8}\right)$ shear wall $\left(\mathrm{xx}^{\prime}\right)$ direction } & $\varphi_{u}$ & 0.24 & 0.30 & 0.34 & 0.39 \\
& $\varphi_{e}$ & 0.02 & 0.02 & 0.02 & 0.03 \\
& $\mu_{\varphi}$ & 16.25 & 15.02 & 14.17 & 13.98 \\
\hline \multirow{3}{*}{$\left(\mathrm{V}_{2}\right)$ shear wall (yy') direction } & $\varphi_{u}$ & 0.20 & 0.31 & 0.37 & 0.42 \\
& $\varphi_{e}$ & 0.01 & 0.02 & 0.03 & 0.03 \\
& $\mu_{\varphi}$ & 17.00 & 15.66 & 14.62 & 14.02 \\
\hline
\end{tabular}

$\varphi_{\mathrm{e}}:$ curvature at the beginning of the plasticization of steels; $\varphi_{\mathrm{u}}$ : curvature at the ultimate strain of concrete; $\mu_{\varphi}:$ curvature ductility factor.

of the seismic energy liberated by the ground.

\section{Conclusion}

The assessment and the analysis of the nonlinear dynamic seismic response behavior for a ten storey structure reinforced concrete braced by shear walls and modeled by SAP2000 software according to Algerian Earthquake Regulations (RPA99/v2003), have led to the following conclusions:

- The identified structure presents a large deformation under the local seismic records, however under the major earthquakes such as that of El Centro, the performance of the deformability requires a very special structural design. It is important to note that Algerian seismic regulations (RPA99/v2003) enable a large deformability equal to $1 \%$ of the storey height in comparison to Eurocode 8 which allows only $0.75 \%$.

- The shear forces obtained under a medium earthquake intensity at the base do not exceed $40 \%$ of the value of the resistant force, unlike that of El Centro, which exceeds $10 \%$.The structure identified indicates a very appropriate and acceptable shear strength under local earthquakes of medium intensity (e.g., Boumerdes), however, under high-intensity earthquakes (e.g., El Centro), the structure shows a very poor seismic performance.

- The bearing capacity of the studied structure shows an inadequate behavior under major earthquake intensities where the structure shows a suffering in their resistance which requires a considerable improvement in the seismic design, unlike that obtained under the local earthquakes.

- The structure has a sufficient ductility, and it decreases substantially with the magnitude of the earthquake.

In general, the results obtained showed that the identified structure has an acceptable performance under the local seismic records of the construction dimensioned by the Regulation Algerian Earthquake (RPA99/v2003). Moreover, under high intensity seismic recording such as that of El-Centro, this performance requires exceptionally a constructive improvement in the recommendations of seismic code. 


\section{References}

[1] Memari, A., Rafiee, S., Motlagh, A., and Scanlon, A. 2001. "Comparative Evaluation of Seismic. Assessment Methodologies Applied to a 32-Story Reinforced Concrete Office Building", JSEE3 (1): 31- 44.

[2] Llera, J. C., Chopra, A. K., and Almazan, J. L. 2001. "Three Dimensional Inelastic Response of an RC Building during the Northridge Earthquake." J. of Struct. Eng., ASCE 127 (5): 482-9.

[3] Gicev, V., and Trifunac, M. D. 2006. Non-linear Earthquake Waves in Seven-Storey Reinforced Concrete Hotel. Report CE 06-03, Los Angeles, California.

[4] Nguyen, X. H., Ile, N., Kotronis, P., Mazars, J., and Reynouard, J. M. 2007. "3D Modelling Structures with Braced Walls: European ECOLEADER Program." In Proceedings of the 7th National Conference AFPS 2007, 158.

[5] Boivin, Y., and Paultre, P. 2010. "Seismic Performance of a 12-Storey Ductile Concrete Shear Wall System Designed According to the 2005 National Building Code of Canada and the 2004 Canadian Standard AssociationA23.3." Can. J. Civ. Eng. 37: 1-16.

[6] RPA-99/version 2003, 2004. Algerian Earthquake Regulations 1999 version 2003. Algiers: DTR-BC National Center Research in Earthquake Engineering (CGS).

[7] Eurocode 2. 2004. Design of Concrete Structures-Part 1-1: General Rules and Rules for Building. CEN, French: European Committee for Standardization.

[8] Boeraeve, Ir. P. 2008. Course in Concrete, Chapter 6: Shear force. Source: Concrete Centre.
[9] Park, R. 1989. "Evaluation of Ductility Structures and Structural Assemblages from Laboratory Testing." Bulletin of the New Zeland National Society for Earthquake Engineering 22 (3): 155-65.

[10] American Society of Civil Engineers ASCE. 2000. Prestandard and Commentary on the Seismic Rehabilitation of Buildings. Rep. No. FEMA 356, Washington, D. C.

[11] ATC (Applied Technology Council) 40. 1996. Seismic Evaluation and Retrofit of Concrete Buildings. California seismic safety commission. Report No. SSC 96-01.

[12] Eurocode 8. 2004. Design of Structures for Earthquake Resistance-Part 1: General Rules, Seismic Actions Rules for Buildings. Brussels, Belgium: CEN.

[13] Wilson, E. L. 2002. Three-Dimensional Static and Dynamic Analysis of Structures: A Physical Approach with Emphasis on Earthquake Engineering. Berkeley, California, USA: Computers and Structures Inc.

[14] NRC. 1984. El Asnam Alegria Earthquake of October 10, 1980. Reconnaissance and engineering report, NRC.

[15] Laouami, N. 2003. "Analysis of Strong Ground Motions Recorded during the 21 May 2003 Boumerdes." Earthquake, Algeria, 7p.

[16] Ayrault, N., Tritsch, J. J., Vuidart, I., and Gaston, D. 2001. Natural Risks, Industrial Environment (DRA 013): Operation A: Synthesis of Risks Attributed to Earthquake, Floods, Landslides, Storms, Disaster. INERIS report.

[17] Choi, E., Nam, T. H., and Cho, B.-S. 2005. "A New Concept of Isolation Bearings for Highway Steel Bridges Using Shape Memory Alloys." Canadian Journal of Civil Engineering 32(5): 957-67. 